\title{
Optimizing Pain Control in a Patient with Lumbar Spinal Stenosis: A Report of Clinical Management
}

\begin{abstract}
Lumbar spinal stenosis is a leading cause of low back pain and one of the most common causes of work absences. Treatment is initialized with narcotic and non-narcotic medications, which have been shown to work in the majority of patients. For those who do not find relief with medications and seek pain/symptom relief, invasive spinal surgery is the last resort.

This case describes the escalation and dose titration of narcotic and non-narcotic medications in a patient with worsening lumbar spinal stenosis that was unable to proceed with surgical intervention for the next several months and had failed his prior outpatient pain regimen. Proper titration of a basal narcotic dose in addition to optimizing non-narcotic medications, including muscle relaxants, proved to better control pain in the interim until surgical intervention. Our case shows how several different teams of physicians and non-physician providers collaborated to optimize pain control using several different treatment regimens with different doses and routes until a safe and effective plan was created for long-term use.
\end{abstract}

Keywords: Spinal Stenosis; Spinal Diseases; Analgesia; Pain Management

Ottimizzazione del controllo del dolore in un paziente con stenosi spinale lombare: un caso clinico

CMI 2018; 12(1): 17-21

https://doi.org/10.7175/cmi.v12i1.1336

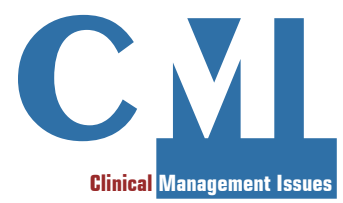

Case Report
${ }^{1}$ University of Wisconsin Hospitals and Clinics, Madison, WI

2 Middleton Veterans Affairs Medical Center, Madison, WI

\section{INTRODUCTION}

The US International Classification of Diseases, $10^{\text {th }}$ Revision, Clinical Modification (ICD-10-CM), has 93,000 different codes for diagnosing patients who seek medical care; and one of the most common reasons for seeking medical attention is low back pain, with a lifetime prevalence of up to $84 \%$ [1]. To further narrow the cause of the broad diagnosis of low back pain, lumbar spondylosis, or degenerative spine disease specifically, is the most common etiology that can profoundly affect functionality and quality of life, and is the biggest culprit of missed work days [2]. Those diagnosed with lumbar spondylosis undergo initial non-operative management consisting of a 6-to-8 week trial with narcotic and non-nar- cotic medications, muscle relaxants, steroid injections, and physical therapy. Although a majority of patients will show improvement with this initial management, those still in

Why do we Describe This Case

In a time where media and the US government claim opioid medications provide more harm than benefit, we shed light on their positive effects. With collaboration and expertise management, it is possible to safely titrate these medications in order to control pain in patients who are otherwise very difficult to treat, while maintaining pain control and patient safety
Corresponding author Raymond E Kennedy ray.e.kennedy.jr@gmail.com

Received: 2 November 2017 Accepted: 23 February 2018 Published: 27 March 2018 


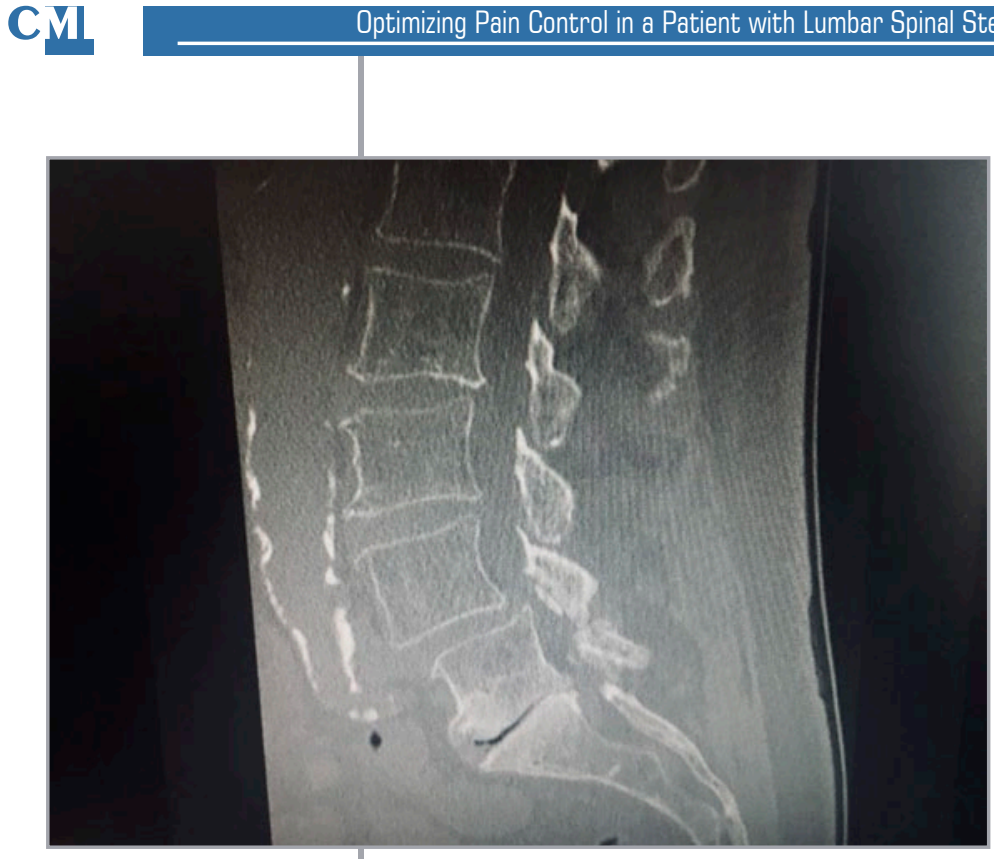

Figure 1. Sagittal computed tomography (CT) image

demonstrating severe central spinal stenosis and spondylolisthesis.

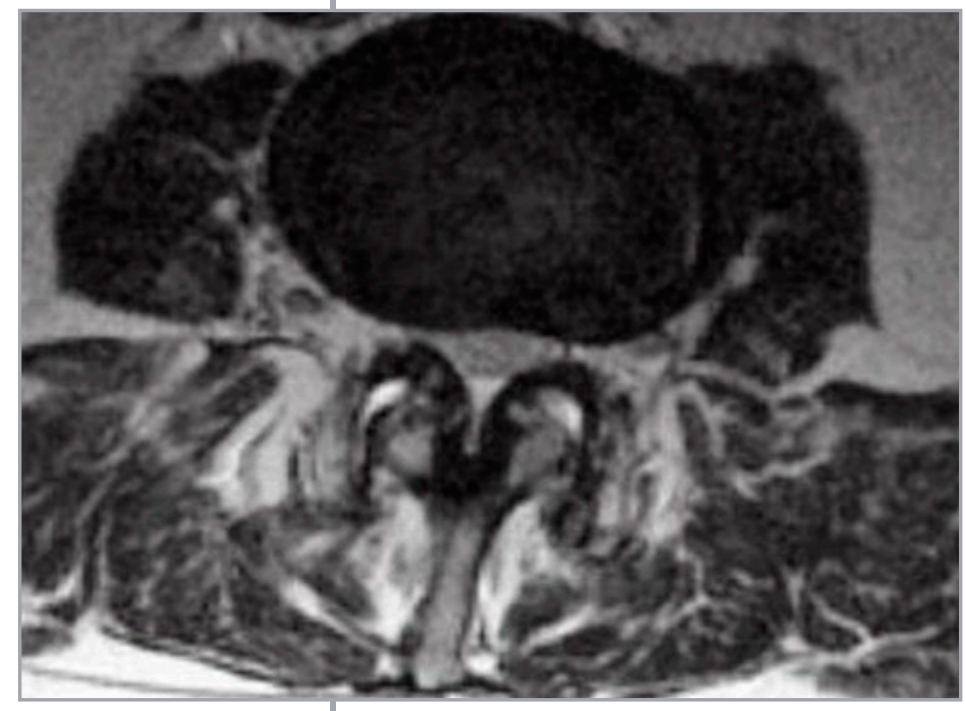

Figure 2. Axial

magnetic resonance imaging (MRI) demonstrating severe central spinal stenosis.

pain seek out a more invasive solution, i.e. spinal surgery [2].

Lumbar spinal stenosis (LSS) is the most common indication for spinal surgery in the aging population [3]. While low back pain may be the initial chief complaint or symptom, other issues arise from the initial cause. Neurogenic claudication (NC) or pseudo-claudication, is commonly due to 
fibrillator (ICD) pacemaker placement, paroxysmal atrial fibrillation on warfarin, and spinal stenosis with chronic back pain treated with $15 \mathrm{mg}$ immediate release (IR) oral morphine at home.

The patient presented with acute worsening of lower back pain, rating as severe while recumbent or standing upright, minimally improved with hip flexion. He believed the symptoms had been progressively worsening, particularly over the past 4-5 days to the point where he is bedridden and unable to ambulate. On the day of presentation, he reported one episode of urinary incontinence, which he described as having been due to an inability to get out of bed in time to make it to the bathroom, due to limitations of his mobility by severe back pain. He denied other instances of urinary or fecal incontinence, saddle anesthesia, fevers, or chills. Of note, anal sphincter tone was normal per the emergency department (ED) physician's exam.

Computed tomography (CT) myelogram 1 month ago showed severe L4-L5 central and foraminal spinal stenosis with complete spinal canal effacement, as well as severe facet arthropathy and multi-level degenerative joint disease (DJD). CT imaging of the lumbar spine taken at that same time is shown in Figure 1.

These changes showed advancement of his disease since prior imaging in 2008. The patient was evaluated by neurosurgery at the time of imaging and was determined to have neurogenic claudication with bilateral L5 radiculopathies with severe L4-L5 central and foraminal spinal stenosis and grade 1 spondylolisthesis (refer to Figures 1 and 2).

Discussions of possible surgical decompression and fusion were deferred until the patient abstained from smoking for at least 4 weeks from admission.

In the $\mathrm{ED}$, he received $0.5 \mathrm{mg}$ intravenous (IV) hydromorphone up to $2 \mathrm{mg}$, with modest relief from pain and was admitted for further pain management (Table I).

As expected, the patient tolerated each pain regimen differently over his 6-day admission. In addition to medications, physical therapy was provided daily to aid the patient in exercise and ambulation with session length progressively increasing throughout admission but was ultimately dependent on patient cooperation. Despite the differing pain strategies, the patient continued to rate his pain as a $6 / 10$ at rest and 10/10 with movement.

\begin{tabular}{|c|c|c|}
\hline Regimen & Medications & $\begin{array}{l}\text { Total Oral Morphine } \\
\text { Equivalents }\end{array}$ \\
\hline 1 & - Morphine IR BID 15 mg & $30 \mathrm{mg}$ \\
\hline 2 & $\begin{array}{l}\text { - Hydromorphone PCA } 10 \mathrm{mg} \\
\text { - Acetaminophen Q6h } 975 \mathrm{mg} \\
\text { - Topical lidocaine }\end{array}$ & $150 \mathrm{mg}$ \\
\hline 3 & $\begin{array}{l}\text { - Morphine ER } 30 \mathrm{mg}-15 \mathrm{mg}-30 \mathrm{mg} \\
\text { - Morphine IR BID } 15 \mathrm{mg} \\
\text { - Gabapentin TID } 200 \mathrm{mg} \\
\text { - Cyclobenzaprine } 5 \mathrm{mg} \text {-acetaminophen } \\
975 \mathrm{mg} \text { Q6h } \\
\text { - Topical lidocaine } \\
\text { - Required additional morphine IR } 30 \mathrm{mg}\end{array}$ & $135 \mathrm{mg}$ \\
\hline 4 & $\begin{array}{l}\text { - Morphine ER TID } 30 \mathrm{mg} \\
\text { - Morphine IR BID } 15 \mathrm{mg} \\
\text { - Gabapentin TID } 300 \mathrm{mg} \\
\text { - Cyclobenzaprine } 5 \mathrm{mg} \text {-acetaminophen } \\
\text { - } 975 \mathrm{mg} \text { Q6h } \\
\text { - Ropical lidocaine } \\
\text { - Required additional morphine IR } 7.5 \mathrm{mg}\end{array}$ & $127.5 \mathrm{mg}$ \\
\hline 5 & $\begin{array}{l}\text { - Morphine ER TID } 30 \mathrm{mg} \\
\text { - Morphine IR BID } 15 \mathrm{mg} \\
\text { - Gabapentin TID } 400 \mathrm{mg} \\
\text { - Methocarbamol TID } 1000 \mathrm{mg} \\
\text { - Acetaminophen Q6h } 975 \mathrm{mg} \\
\text { - Topical lidocaine }\end{array}$ & $120 \mathrm{mg}$ \\
\hline \multicolumn{2}{|c|}{$\begin{array}{l}\text { The patient's home medication consisted } \\
\text { regimen } 1 \text { (see Table I), which no longer } \\
\text { eated his worsening back pain and this }\end{array}$} & $\begin{array}{l}\text { Table I. Pain medication } \\
\text { regimens with } 25 \% \text { cross } \\
\text { tolerance conversion }\end{array}$ \\
\hline
\end{tabular}

medication failure with progressive disease was ultimately what brought him to the emergency department. For advanced pain control, regimen 2 (see Table I) was implemented on admission and proved effective in decreasing pain but was at the expense of the patient becoming bedridden, dependent on the PCA (patient-controlled analgesia) pump and uncooperative in participating with physical therapy. The PCA was discontinued and the patient was transitioned to oral medications with strict limitations to avoid further IV opioid analgesia.

Chronic pain services were also consulted at this stage in treatment, with recommendations to up-titrate non-opioid medications in addition to the current regimen. Despite increasing the dose of extended-release morphine, the total amount of oral morphine equivalents decreased.

\section{DISCUSSION}

As the media continues to promote the war on opioids and attempts to decrease the number of medical prescription nar-
$\mathrm{BID}=$ bis in die (twice a day); $\mathrm{ER}=$ extended release; $\mathrm{IR}=$ immediate release; $\mathrm{PCA}=$ patientcontrolled analgesia; $\mathrm{Q} 6 \mathrm{~h}=$ quaque sex hora (every 6 hours); TID = ter in die (thrice a day) 
cotics, it is becoming increasingly difficult to adequately control pain in patients who would benefit from a tailored regimen of pain medications. The current media has caused many physicians to become "gun shy" when prescribing opioids, and, for those that do, the doses may be too low to cause any benefit. This is ultimately leading to a time in medicine where useful medication will be set aside for "safer" alternatives.

In our case, pain medications were tailored to the desired effect: a balance between pain control and patient well-being. Initial regimens consisted of shorter acting, and patient-controlled analgesics. While pain was controlled with these methods, fear for the patient's safety and well-being caused for a change in approach. Starting off with a low basal rate with intermittent short-acting dosing available for breakthrough should be used as a starting point for any patient with chronic pain, as it aims to control pain long term while also starting at low enough doses to allow for titration based on patient response. The optimal regimen in our case consisted of a higher basal rate of opioids with the addition of short-acting opioids and several non-narcotic medications. Ironically, the higher dose of basal rate morphine provided a smaller daily amount of opioids, while maintaining adequate control of pain.

The reason as to why this regimen succeeds over the other attempts can be due to several reasons: a higher basal rate of pain control was achieved with the extendedrelease morphine; an effect of medically optimizing non-opioid medications; or perhaps, a synergism between the two. Regardless identifying the exact cause, pain was ultimately under better control based on decreased additional dosing required overnight, increased length of physical therapy sessions, and clinical examination.

As the leading cause of drug abuse deaths in America's epidemic, the first step of identifying the problem has been accomplished. However, the next several steps required to solve or at least minimize this nation-wide problem is not as simple. The nation's current focus is on prescription opioids administered by physicians. While this is only half of the problem, the other being illicit production, distribution and abuse of opioids, the already heavily regulated industry of prescription medications is much easier to regulate and restrict further, and that is exactly what is happening.

With greater checks-and-balances surrounding the administration of certain prescription medications (i.e. with PDMP's, tighter prescription laws for physicians, etc.), it should be concluded that this epidemic would immediately cease to exist. In reality, regardless of the number of restrictions placed on physicians who only intend to treat their patient, the abuse of prescription medications will remain astronomical. The only foreseeable difference is in the ratio of abuse potential from prescribed medications versus illicit forms, and as tighter control is placed on prescriptions, the numbers will sway in favor of illicit abuse as long as the medications can be produced and distributed amongst the community.

Key Points

- Narcotics can safely and effectively manage pain in patients long term

- Non-opioid medications can provide a synergistic effect in pain control and help reduce the overall dose of opioids while achieving the desired pain goal

- Collaboration with physicians, pain specialists, and non-physician providers is crucial for successful management

- Multiple changes in treatment plans may be necessary to discover a regimen that is safe and beneficial

- Patient safety and comfort should be the main priorities in treating chronic pain

\section{Funding}

This article has been published without the support of sponsors.

Conflicts of Interests

The authors declare they have no competing financial interests concerning the topics of this article. 


\section{REFERENCES}

1. Waddell G. The Back Pain Revolution. ed. 2. London: Churchill Livingstone, 2004

2. Parker SL, Godil SS, Mendenhall SK, et al. Two-Year Comprehensive Medical Management of Degenerative Lumbar Spine Disease (Lumbar Spondylolisthesis, Stenosis, or Disc Herniation): A Value Analysis of Cost, Pain, Disability, and Quality of Life: Clinical Article. J Neurosurg Spine 2014; 21: 143-9; https://doi.org/10.3171/2014.3.SPINE1320

3. Deyo RA. Treatment of Lumbar Spinal Stenosis: A Balancing Act. Spine J 2010; 10: 625-7; https://doi.org/10.1016/j.spinee.2010.05.006

4. Markman JD, Geandter JS, Frazer ME, et al. A Randomized, Double-Blind, PlaceboControlled Crossover Trial of Oxymorphone Hydrochloride and Propoxyphene/Acetaminophen Combination for the Treatment of Neurogenic Claudication Associated With Lumbar Spinal Stenosis. Spine 2015; 40: 684-91; https://doi.org/10.1097/BRS.0000000000000837

5. Barlas S. U.S. and States Ramp Up Response to Opioid Crisis: Regulatory, Legislative, and Legal Tools Brought to Bear. P T 2017; 42: 569-92

6. Institute of Medicine. (US) Committee on Advancing Pain Research, Care, and Education. Relieving Pain in America: A Blueprint for Transforming Prevention, Care, Education, and Research. Washington, DC: National Academies Press, 2011 